\title{
Application of nanodiagnostics in point-of-care tests for infectious diseases
}

This article was published in the following Dove Press journal:

International Journal of Nanomedicine

4 July 2017

Number of times this article has been viewed

\section{Yongzhong Wang' \\ Li Yu ${ }^{2}$ \\ Xiaowei Kong' \\ Leming Sun ${ }^{3}$}

'Anhui Key Laboratory of Modern Biomanufacturing, School of Life Sciences, Anhui University, Hefei, Anhui, People's Republic of China, 2Department of Microbiology and Parasitology, Anhui Provincial Laboratory of Microbiology and Parasitology, Anhui Key Laboratory of Zoonoses, Anhui Medical University, Hefei, Anhui, People's Republic of China; ${ }^{3}$ Department of Biomedical Engineering, The Ohio State University, Columbus, OH, USA
Correspondence: Leming Sun Department of Biomedical Engineering, The Ohio State University, 270 Bevis Hall, 1080 Carmack Road, Columbus, $\mathrm{OH} 43210$, USA

Tel + I 5085427779

Email sun.1342@osu.edu

\begin{abstract}
Although tremendous efforts have been put into the treatment of infectious diseases to prevent epidemics and mortality, it is still one of the major health care issues that have a profound impact on humankind. Therefore, the development of specific, sensitive, accurate, rapid, low-cost, and easy-to-use diagnostic tools is still in urgent demand. Nanodiagnostics, defined as the application of nanotechnology to medical diagnostics, can offer many unique opportunities for more successful and efficient diagnosis and treatment for infectious diseases. In this review, we provide an overview of the nanodiagnostics for infectious diseases from nanoparticle-based, nanodevice-based, and point-of-care test (POCT) platforms. Most importantly, emphasis focused on the recent trends in the nanotechnology-based POCT system. The current state-of-the-art and most promising point-of-care nanodiagnostic technologies, including miniaturized diagnostic magnetic resonance platform, magnetic barcode assay system, cell phone-based polarized light microscopy platform, cell phone-based dongle platform, and paper-based POCT platform, for infectious diseases were fully examined. The limitations, challenges, and future trends of the nanodiagnostics in POCTs for infectious diseases are also discussed.
\end{abstract}

Keywords: nanodiagnostics, nanoparticles, nanodevices, point-of-care test, infectious diseases, pathogens

\section{Introduction}

Infectious diseases are mainly caused by pathogenic microorganisms including viruses, fungi, bacteria, and parasites that have a profound impact on humankind because of their unique characteristics such as the ability to rapidly multiply in number, unpredictability, and evolutionary advantage ${ }^{1-7}$ For instance, there were more than 200 million people infected with malaria around the world in $2015 .{ }^{8}$ Many other infectious diseases such as viral hepatitis, dengue fever, cholera, severe respiratory syndrome, and avian influenza ${ }^{5}$ have posed a great threat to human life and caused more than half of deaths around the world. ${ }^{9}$ More importantly, the prevalent infectious diseases have caused continuous increase of morbidity and mortality rates in the developing nations. ${ }^{10}$ Although these diseases are generally localized to a particular region, they can spread worldwide easily because of increased global travel. Thus, there is an urgent need to develop new and novel diagnostics to detect infectious diseases to stop the spread, secure public health, and promote treatment.

The ideal diagnostic tools for infectious diseases should have the ability to be sensitive, rapid, specific, accurate, robust, low-cost, and user-friendly., ${ }^{2,5}$ Over the past half-century, many improvements in the diagnosis of infectious diseases have been achieved. The conventional diagnosis techniques include culture and microscopy, immunology, as well as the polymerase chain reaction (PCR) strategies. ${ }^{1-14}$ 
These techniques have significantly contributed to the diagnosis of infectious diseases and greatly promoted the prevention and treatment for various infectious diseases. However, they have also shown many limitations, such as being slow, expensive, inaccurate, and require skilled technicians. Especially in the developing countries, these techniques have further limitations because of the poor resources and lack of skilled persons. Therefore, novel and new diagnostic techniques need to be developed for the prevention and treatment of infectious diseases to meet the unmet demands, such as early detection, high sensitivity, and the potential for point-of-care tests (POCTs) for among families and in community clinics worldwide. ${ }^{15}$

Nanotechnology has advanced the development of many fields because of the unique properties of nanomaterials in optical, mechanical, magnetic, catalytic, and electrical perspectives. ${ }^{16-18}$ For the past several decades, biomedical applications including tissue engineering, drug delivery, bioimaging, and nanodiagnostics have been promoted by the nanotechnology significantly. ${ }^{19-22}$ Among these applications, nanodiagnostics have drawn more and more attention for the infectious diseases because of their unique characteristics in early detection, high sensitivity, and the potential for POCT..$^{15}$ Toward this direction, lots of novel and efficient nanodiagnostics for infectious diseases have been developed. Most importantly, these nanotechnology-based systems have potential to develop the POCT platforms with portable, robust, and affordable properties to detect infectious diseases in the developing countries. For instance, researchers have developed a smartphone dongle as a POCT system to test infectious diseases. ${ }^{15}$ They have demonstrated that a full immunoassay traditionally operated in the laboratory can be integrated into a smartphone accessory to achieve the nanotechnology-based POCT for infectious diseases. ${ }^{15}$ Therefore, the nanodiagnostics in POCT have shown many promising advantages in the quick detection of infectious diseases and could be realized in the near future for different clinical requirements.

In this review, we focus on the recent trends in nanodiagnostics for infectious diseases, especially for the pointof-care (POC) nanodiagnostics that have the most potential to fight infectious diseases. We briefly introduce several major infectious diseases including viruses-caused diseases, bacteria-caused tuberculosis, and parasite-caused malaria. The conventional diagnosis techniques including culture and microscopy, immunology, and PCR are discussed and utilized to illustrate the current standards and limitations for the diagnosis of infectious disease. Finally, the current stages and recent efforts in nanodiagnostics for infectious diseases, including nanoparticle-based, nanodevice-based, and the most important nanotechnology-based POCT, are discussed to advance the development of novel and new approaches to diagnose and treat infectious diseases in the future.

\section{Infectious diseases}

\section{Viruses-caused infectious diseases}

Viruses are small infectious capsules with genetic materials inside, which can replicate only inside of the living cells. All life types can be infected by viruses from microorganisms to plants and animals. There are many viruses, such as human immunodeficiency virus (HIV), hepatitis B virus (HBV), and hepatitis $\mathrm{C}$ virus (HCV), that can cause the lifethreatening infectious diseases. ${ }^{23,24}$ At the end of 2015, there were $\sim 36.7$ million people affected by HIV globally, which is still one of the major causes of morbidity and mortality worldwide. ${ }^{25} \mathrm{HIV}$ is an RNA virus that can destroy immune cells such as dendritic cells, macrophages, and T cells, ${ }^{5}$ and is extremely hard for the diagnosis and treatment because of their high mutation rate. Currently, there is still no reliable therapy for HIV infection, which makes the diagnosis very important for AIDS patients. Several approaches have been invented to detect HIV, such as enzyme Western blot, PCR, and enzyme immunoassay. ${ }^{26}$ However, none of them are suitable for the real demand in clinics. For example, those HIV detecting platforms require expensive laboratory instruments and skilled technicians. The detection speed is also not rapid enough. Most of these techniques need several weeks to obtain a result, but the viral RNAs could be theoretically detected in the blood after 9 days from the infection. ${ }^{24}$ Thus, the early and efficient diagnosis of HIV is still urgently needed.

Viral hepatitis has affected $\sim 400$ million people worldwide, 10 times more than the number of people infected with HIV. ${ }^{27}$ Among them, HBV and HCV have already caused major public health issues worldwide. HBV can be transmitted through the body fluids or blood, and eventually infects people by attacking the liver system, and results in acute and chronic hepatitis diseases. HCV is another blood-borne virus, also causing acute and chronic hepatitis infection. It is normally transmitted through unsterilized medical devices, unsafe injection tools, and transfusion of infected blood. Many strategies have been developed for the diagnosis of HBV and HCV, such as PCR-based and immunology-based assays. ${ }^{28,29}$ Although these methods have improved the traditional tests with more sensitivity and 
efficiency, they still have their own shortcomings, including time-consuming, expensive instruments, requirements of specific and complicated protocols, and so on. Therefore, more novel and unique techniques or platforms need to be developed to meet the unmet clinical demands.

\section{Bacteria-caused infectious diseases}

There are many bacteria-caused infectious diseases such as tuberculosis and cholera, which have posed a great threat to human life worldwide, especially in developing countries. Tuberculosis is caused by Mycobacterium tuberculosis (MTB), which mainly affects the lungs. It can spread from person to person by the tuberculosis germs being propelled into the air through a cough, spit, or sneeze. ${ }^{30}$ Just a few of these germs could infect a person with tuberculosis. Tuberculosis is one of the top 10 causes of death in the world. In 2015 , there were $\sim 10$ million new tuberculosis infections and 1.8 million people died from the disease worldwide. ${ }^{31}$ This disease was responsible for more deaths than HIV and malaria. Diagnosis of tuberculosis is very important in order to control the spread of MTB and to treat the infected person. Many strategies have been invented for the diagnosis of tuberculosis disease. ${ }^{30}$ In the early stages, active tuberculosis was diagnosed by culturing the tuberculosis bacteria; ${ }^{32}$ however, it may take several weeks to get a result. Recently, people have also developed blood-based diagnostic methods to detect tuberculosis disease using immunology techniques that have higher sensitivity and specificity, ${ }^{36}$ but the requirement of skilled technicians and expensive equipment makes it unsuitable in developing countries.

\section{Parasite-caused infectious diseases}

The parasite organisms can cause many infectious diseases such as malaria, leishmaniasis, and trypanosomiasis, resulting in high morbidity and mortality in developing countries. Among them, malaria is caused by different parasite Plasmodium species, ${ }^{33,34}$ and is an acute public health problem that needs to be eliminated. In 2015, worldwide, there were $\sim 212$ million newly infected malaria patients and $\sim 429,000$ patients died. ${ }^{8}$ Malaria can spread by mosquitoes and is particularly dangerous for pregnant women and children because of their poor immune system. ${ }^{35}$ Several approaches have been developed to diagnose malaria, including microscopy, immunology-based, and PCR. ${ }^{36,37}$ For a long time, microscopy was the most popular approach to diagnose malaria, especially in developing countries. ${ }^{34}$ Only a microscope and a drop of blood to check the malaria-induced parasites are required. However, this technology has many drawbacks for the detection of malarial disease. It is not easy to recognize different species of malarial parasites without skilled technicians. Low concentrations of parasites can also be extremely hard for diagnosis. A few decades ago, PCR was demonstrated as the most efficient method for the detection of malaria with low levels of parasites. ${ }^{38}$ However, it needs complicated operating skills and expensive equipment that is not usually available in poorly-resourced regions in developing countries.

\section{Conventional diagnosis for infectious disease}

Currently, there are three different types of approaches developed for the detection of the infecting pathogens, including culture and microscopy, immunology, and PCR. For decades, the culture and microscopy approach was the most common strategy for the detection of infecting agents, by which microorganisms were cultured in a growth medium, followed by observation either using the naked eye or under the microscope. The observation could be based on the shape, size, and color of the colony formed. Without the necessity of culture process, the microscopy also has the ability to recognize and detect the pathogenic agents from patient samples directly, such as blood, urine, and stool. The immunologybased strategy has been widely utilized for disease diagnosis through the detection of specific bindings between the antibody and antigen. Different immunology-based methods have been developed for the diagnosis of infectious diseases, including enzyme-linked immunosorbent assay (ELISA), fluorescent immunoassays, magnetic immunoassays, radioimmunoassays (RIA), lateral flow immunoassays, and so on. For instance, the enzyme immunoassays, followed by Western blot techniques to detect the immunoglobulin $\mathrm{M}$ antibodies in the serum from patients, have been used as a current gold standard for HIV diagnosis. ${ }^{39}$ In recent years, the PCR method has been commonly utilized for amplifying RNA or DNA from pathogens for the diagnosis of infectious diseases. It can detect a single targeted DNA sequence with 1 million fold in 1 hour. ${ }^{9}$ Currently, there are three PCR-based approaches used to diagnose infectious diseases, including multiplex PCR, reverse transcriptase PCR, and real-time PCR. Due to the high speed, specificity, and sensitivity, real-time PCR has been widely utilized in infectious diseases diagnosis.

Like a coin having two sides, the conventional diagnostic approaches have advantages, such as specificity, robustness, sensitivity, and accuracy, but also have drawbacks, especially for the earlier and rapid detection of infectious diseases. 
For one thing, the tests are time-consuming, which is an obvious negative characteristic. As for the culture and microscopy method, primary tests may take 2-3 days, and the final test could take up to 7-10 days to confirm the diagnostic results. To obtain useful results, pathogens in the original samples from patients or the cultured pathogens at final stages should pass a certain level when the culture and microscopy method was used. Otherwise, it could be undetectable or result in false-negative conclusions. In addition, requirements of complicated and expensive facilities, high cost, low portability, and potential cross contamination are other typical limitations for these conventional diagnostic approaches. These drawbacks make them particularly unsuitable for the early diagnosis or POCT for infectious diseases. Therefore, more and more novel technologies or approaches such as nanodiagnostics could have the opportunity to overcome these challenges and eventually be developed to be an ideal strategy to meet the unmet demands in the clinical diagnosis of infectious diseases.

\section{Nanodiagnostics for infectious diseases}

Nanodiagnostics, defined as the use of nanotechnology in diagnostic applications, has been extensively studied to meet the requirements of clinical diagnostics with high sensitivity and earlier detection of various diseases. ${ }^{40}$ The high surface-tovolume ratio of nanostructures makes them very suitable to attach lots of targeting molecules that improve the sensitivity of the detecting results. ${ }^{41,42}$ The unique properties of nanomaterials or nanostructures confer the nanodiagnostic platforms on an ability of rapid and real-time detection by only using very small volumes of samples from patients. Thus, nanodiagnostic approaches have huge potential to be low-cost, user-friendly, and robust systems. Currently, most of the nanodiagnostic applications are focused on the detection of pathogens in infectious diseases and cancer biomarkers in cancer therapy. For the infectious diseases, the nanodiagnostic platforms have the ability to achieve reliable and rapid conclusions with simple and portable devices just by using blood, sputum, or urine samples from patients. ${ }^{43}$ In addition, the sensitive nanodiagnostics platforms, with much potential to be robust, affordable, and reproducible, could be suitable for applications in the diagnosis of infectious diseases, particularly in resource-poor areas in the developing countries.

\section{Nanoparticle-based diagnosis for infectious diseases}

There are many nanoparticles, particularly fluorescent nanoparticles, metallic nanoparticles, and magnetic nanoparticles, which have been successfully utilized for the diagnosis of infectious diseases. Fluorescent nanoparticles are sensitive and photostable fluorescent probes that can be used to label many different biological targets. They have been demonstrated as new strategies to perform disease diagnosis in real time through bioimaging or sensing activities. Quantum dots are semiconductor-based fluorescent nanostructures with the size around 1-10 nm, which have many novel properties, such as photostability, high quantum yield, and bright. The fluorescence functions of quantum dots can be easily tuned through the changes in their size and composition. As a successful example, HBV has been diagnosed simply and sensitively through the dot immunoassay using the quantum dots nanobeads (QDNBs), as shown in Figure $1 .^{44}$ The fluorescent signal from the QDNBs could be amplified because of encapsulation of many quantum dots in an individual nanoparticle. After immobilization of the hepatitis B surface antigens on the porous polyvinylidene difluoride, the antibody-conjugated QDNBs as molecular probes were incubated with the antigens together, and the fluorescent dots were then recorded using a CCD camera under the illumination of UV lamp. It has been demonstrated that this simple QDNBs-based diagnostic system can be used to detect as low as $78 \mathrm{pg}$ of hepatitis B surface antigen, indicating that the diagnosis of infectious diseases through the QDNBs is very sensitive and potentially useful for the detection of other biomarkers in a very complex biological environment. ${ }^{44}$

The most used metallic nanoparticles in the diagnosis applications are gold and silver nanoparticles. These metallic nanoparticles could emit intense absorption when excited with electromagnetic radiation. ${ }^{41}$ The gold nanoparticles are the first nanomaterials as nanodiagnostics for the detection of DNA in $1996 .{ }^{45}$ The changes in the color of gold nanoparticles in solution from red to blue have been demonstrated after DNA-guided aggregations, which make them ideal nanomaterials for nanodiagnostics because of their unique color changes and other chemical and physical properties. Many different molecules, such as antibodies, antigens, and enzymes, could be conjugated with gold nanoparticles as electrochemical labels, optical probes, and signal transfer amplifiers for the diagnosis of various diseases. For instance, the gold nanorods have been used to diagnose HIV through their second-order nonlinear optical properties. ${ }^{46}$ A 100 picomolar target DNA can be recognized by a $145-$ mer oligonucleotide probe, which was recorded by a hyperRayleigh scattering (HRS) spectroscopy with high sensitivity and selectivity. The gold nanorods have demonstrated a rapid, simple, and efficient detection of single-base-mismatch HIV-1 virus DNA through the HRS intensity changes. ${ }^{46}$ 


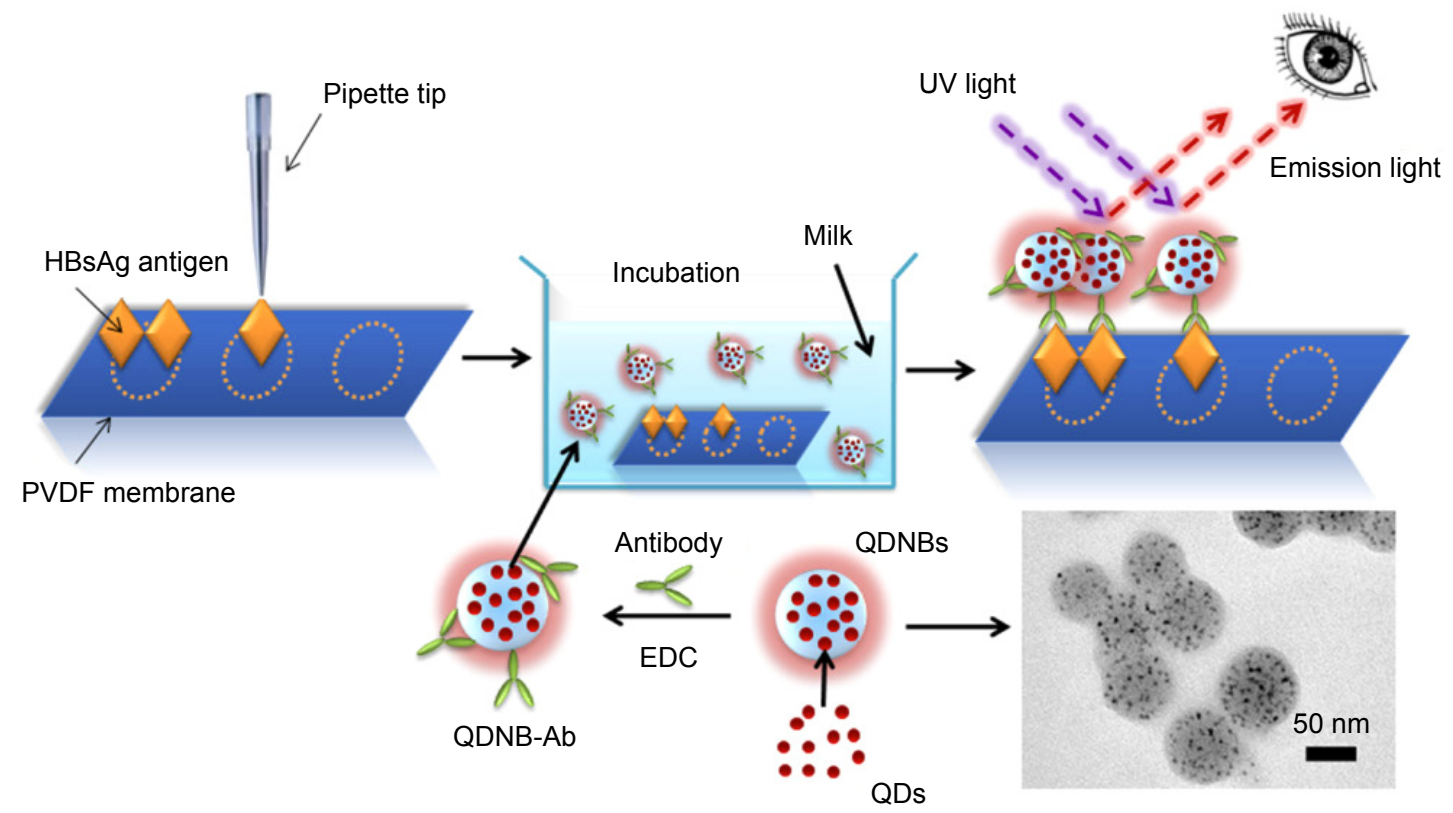

Figure I Schematic illustration of the detection of HBsAg using QDNBs for the diagnosis of hepatitis B.

Notes: Reprinted by permission from Zhang P, Lu H, Chen J, Han H, Ma W. Simple and sensitive detection of HBsAg by using a quantum dots nanobeads based dot-blot immunoassay. Theranostics. 2014;4(3):307-315. Copyright @ 2014 Ivyspring International Publisher. Creative Commons license available at: https://creativecommons.org/ licenses/by-nc/4.0/legalcode. ${ }^{44}$

Abbreviations: Ab, antibody; EDC, I-ethyl-3-(3-di-methylaminopropyl) carbodiimide hydrochloride; HBsAg, hepatitis B surface antigen; PVDF, polyvinylidene difluoride; QDs, quantum dots; QDNB, quantum dots nanobead; UV, ultraviolet.

A similar HRS technique with gold nanoparticles has also been developed to detect $\mathrm{HCV}$ for infectious diseases. ${ }^{47}$ The gold nanoparticles were conjugated with HCV ssRNA tagged with rhodamine $6 \mathrm{G}$, through which as low as 80 picomolar HCV ssRNA could be detected, and the selectivity can reach a single base-pair mismatch. ${ }^{47}$

Magnetic nanoparticles have been successfully applied in many biomedical applications, such as bioimaging, cancer therapy, and nanodiagnostics. ${ }^{48-52}$ This diagnosis is based on the enhanced separation and detection of aligned magnetic nanoparticles bonded with targeting agents under an applied magnetic field. ${ }^{9}$ As commonly used magnetic nanoparticles, iron oxide nanoparticles, composed of magnetite or maghemite cores, have been used as contrast agents for magnetic resonance imaging. The surface of the iron oxide nanoparticles can usually be modified and conjugated with antibodies, proteins, and nucleic acids, in order to detect many different infecting pathogens, such as viruses, bacteria, and parasites. As a successful example, the magnetic nanoparticles with iron oxide core and silver shell have been demonstrated for the efficient and early diagnosis of malaria, an infectious disease. ${ }^{53}$ These magnetic nanoparticles showed an ability to detect $\beta$-hematin crystals, an equivalent of hemozoin biocrystals, through the magnetic field-enriched surface-enhanced resonance Raman spectroscopy. The hemozoin has been recognized as a biomarker for malaria infection, and could be used for early diagnosis of malaria.
Through an external magnetic field, the detection limit of $\beta$-hematin can reach as low as $5 \mathrm{nM}$, which is around 30 parasites in $1 \mu \mathrm{L}$ of blood samples from the early status of malaria-infected patients. ${ }^{53}$

\section{Nanodevice-based diagnosis for infectious diseases}

Although numerous applications using simple nanoparticlebased nanodiagnostics for infectious diseases have been extensively studied, they are still far from meeting the real demands in the clinic. As many infecting pathogens, such as HIV, and Plasmodium parasites, always have multiple strain types, and many patients could be infected with multiple pathogens such as HIV and HBV together, more advanced nanodiagnostics focusing on the development of the complicated diagnosis of infectious diseases are greatly required. Currently, there are many techniques integrated with the nanotechnology to build nanodevice-based diagnostic platforms for the diagnosis of infectious diseases. Among them, lab-on-a-chip and microfluidics techniques have shown good promise for the detection of infectious diseases. ${ }^{54,55}$ Through these techniques, multiple assays could be integrated into one single device, ${ }^{56,57}$ resulting in a decrease in the volume of samples from infected patients, the consumption of materials, and the analysis time. These advantages of the integrated systems could greatly potentiate to build low-cost and portable devices. ${ }^{58-61}$ 
A successful integrated nanodevice with high-throughput and multiplexed detecting ability for the most important blood-borne infecting agents such as HIV, HBV, and HCV in serum samples has been developed through the combination of nanotechnology (quantum dots) and microtechnology (microfluidics) (Figure 2). ${ }^{62}$ Through this diagnosis, multiple pathogens could be detected precisely using the human serum samples simultaneously. The detection limitation of this diagnosis for the requiring serum volumes could be as low as $100 \mu \mathrm{L}$, and the detection could be finished within 1 hour, and the sensitivity is more than 50 times of the US Food and Drug Administration currently approved platforms. ${ }^{62}$ Another successfully developed nanodiagnostic platform for HIV was based on the detection of viral envelope glycoprotein gp120 using a mesoporous silica-based nanodevice. ${ }^{63}$ The nanosystems were coated with the human host cell surface receptor CD4 or an 18-mer peptide that mimics the gp120 binding region. These surface modifications confer the nanodevices to interact with the gp120 from HIV. Through the functional modification, this diagnostic system could potentiate to diagnose HIV infection, and even facilitate drug or vaccine development. ${ }^{63}$

The integrated nanodevices could also be used to enrich the pathogens or pathogen DNAs, and eventually enhance the sensitivity of the conventional diagnostic approaches. As the low concentration of parasites in blood from early-stage malaria patients is always a big challenge for the diagnosis purposes, the conventional approaches, such as real-time PCR, still remain unpractical for the real clinical diagnosis of early-stage malaria patients. To this end, a shear modulated inertial label-free microfluidic system has been developed to concentrate the malaria parasites in blood for a more reliable and specific PCR diagnosis. ${ }^{64}$ The ring-shape malaria parasites from lysed blood samples were isolated using the
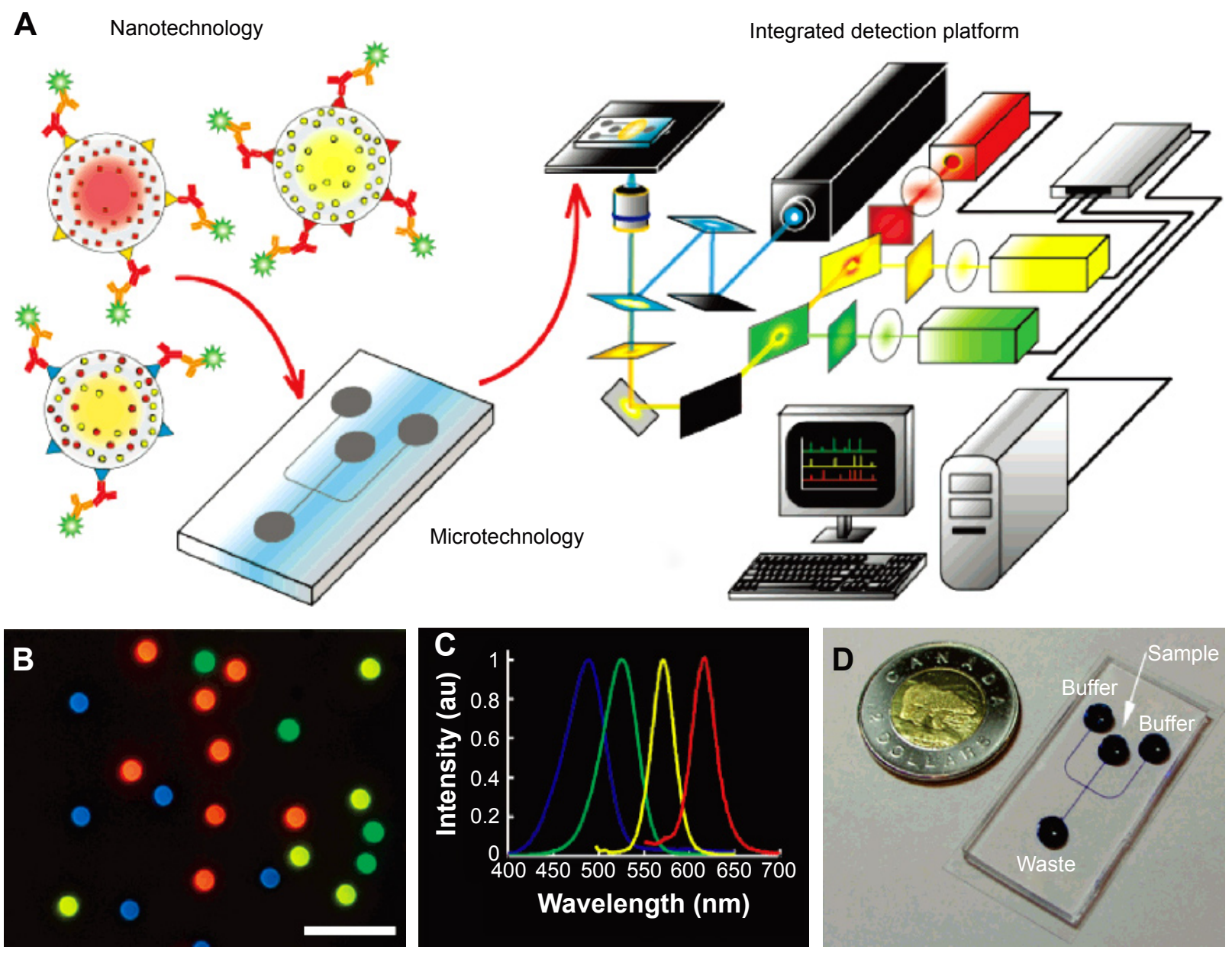

Figure 2 (A) Diagnostic scheme of nanodevice-based detection of blood-borne infectious diseases. (B) Quantum dot barcodes with different color fluorescence image (scale bar $=20 \mu \mathrm{m}$ ). (C) Normalized quantum dot emission profiles for the quantum dots used for the barcodes in B. (D) The prototype of the polydimethylsiloxane microfluidic chip. Notes: Reprinted with permission from Klostranec J, Xiang Q, Farcas G, Lee J, Rhee A, Lafferty E, Perrault S, Kain K, Chan W. Convergence of quantum dot barcodes with microfluidics and signal processing for multiplexed high-throughput infectious disease diagnostics. Nano Letter. 2007;7(9):28I2-28I8. Copyright (C) 2007 American Chemical Society. ${ }^{62}$ 
high aspect ratio (height-to-width ratio) microchannel with pinched flow dynamics. The high shear rate in the channel width from these nanodevice-based systems made the white blood cells stay at the inlet and then concentrated around the sidewalls of the channels. Thus, the malarial parasites could continue to flow to the end and finally reach a high concentration. Using these concentrated parasites, the recorded signal from the real-time PCR showed around 2-time increase compared to the original malarial parasites in whole blood without removing white blood cells.

Through the isolation and enhancement strategies, the integrated nanodevices not only increase the reliable and specific diagnosis of malaria, an infectious disease, as mentioned above, but also potentiate to facilitate the diagnosis of other pathogens diagnosis. ${ }^{64}$ The immunofluorescence nanodevices provide another successful example to enhance the diagnosis of human tuberculosis by using the integrated nanodevices. ${ }^{65,66}$ Researchers have tried to enrich the extracellular DNA on nanostructured tips through the combination of dielectrophoresis and capillary actions. ${ }^{66}$ The dielectrophoresis was first used to attract DNA and other molecules around the nanotips, and then the capillary action could capture the DNA onto the nanotips. Through this enrichment procedure, the limitation of this detection for DNA is around $6.7 \mathrm{pg} / \mathrm{mL}$. However, these nanodevice-based diagnostic platforms were not specific enough for the detection of small volume samples. To improve the specificity, a new diagnostic system, composed of immunofluorescence microtip sensor modified with genus-specific antibodies at their surfaces, was, therefore, invented for the detection of M. tuberculosis complex cells in sputum. ${ }^{65}$ By this new device, the target pathogens could be concentrated at the surfaces of the microtips using flow electric field and flow circulation. It has been demonstrated that this diagnostic platform could be used to diagnose tuberculosis in human sputum specifically through the combination of immune-affinity binding, electric field, and streaming flow techniques. The detection limitation was comparable to PCR, but more simple and faster. The diagnosis can be finished in 25 minutes without extra preparation steps, such as bacteria culture, centrifugation, and DNA amplification. In combination with portable and low-cost optical microscopy in the future, these platforms could be useful for the fast and specific POCT diagnosis for infectious diseases.

\section{Application of nanodiagnostics in POCT for infectious diseases}

The POCT could be defined as bedside diagnosis through mobile or portable devices, by which diagnostic results should be concluded rapidly for patients and their physicians. ${ }^{67}$ The World Health Organization has given the "ASSURED" criteria to guide the development of POCT, which is affordable, sensitive, specific, user-friendly, rapid and robust, equipmentfree, and deliverable to end users. ${ }^{68}$ Those devices that satisfy the ASSURED standard should be able to provide same-day diagnosis and promote the decision making immediately. ${ }^{69}$ The POC diagnostic platforms have drawn more and more attention for the detection of infectious diseases because of their rapid, low-cost, and portable properties. ${ }^{70}$ These features are very important for the detection and control of infectious diseases, particular in low-resource areas in developing countries.

Although many nanoparticle-based and integrated nanodevice-based diagnoses with the high sensitivity for infectious diseases have shown good potential for the bedside tests, they still have a long way to come to meet the unmet needs in the POCT for infectious diseases because many of current nanodiagnositic systems need external resources such as electrochemical, optical, and magnetic resonance sensing systems, to detect the infecting agents for infectious diseases. These features force them to associate with expensive instruments and skilled technicians, indicating they are not suitable for the real needs in the POC diagnosis. To overcome these disadvantages, many efforts have been made to meet the "ASSURED" standard for the infectious disease diagnosis, such as the minimization of the detecting platforms or using the visible readout assays. In this review, the most important nanodiagnostics-based strategies and technique platforms proposed to develop novel POC diagnosis for the detection of pathogenic agents for infectious diseases, including diagnostic magnetic resonance (DMR) platform, ${ }^{71,72}$ magnetic barcode assay systems, ${ }^{73,74}$ cell phone-based polarized light microscopy platform, ${ }^{75,76}$ cell phone dongle platform, ${ }^{15,77}$ and paper-based POCT platform are introduced and discussed. ${ }^{78,79}$ These novel nanotechnology-based diagnostic platforms, with the advantages and drawbacks according to the ASSURED criteria listed in Table 1, are currently the most promising POC diagnosis for various infectious diseases.

\section{Miniaturized diagnostic magnetic resonance platform}

The electrical engineering and microprocessor have strong powers to miniaturize the POCT devices through microtechnology and nanotechnology. A novel and miniaturized DMR platform has been developed for a rapid, quantitative, and multiplexed detection of infecting pathogens for infectious diseases. ${ }^{71}$ The DMR systems with potential portable properties have the ability to test unprocessed biological samples 
Table I The overview of POC nanodiagnostic system for infectious diseases

\begin{tabular}{|c|c|c|c|c|}
\hline POC nanodiagnostic system & Components & Advantages & Drawbacks & References \\
\hline Diagnostic magnetic resonance & Magnetic nanoparticles & Rapid & Not affordable & 7I, 72 \\
\hline platform & NMR system & Sensitivity & Not portable & \\
\hline \multirow[t]{3}{*}{ Magnetic barcode assay systems } & Magnetic nanoprobes & Rapid & Not affordable & 73,74 \\
\hline & Microfluidic system & Sensitivity & Needs extra DNA & \\
\hline & & Specificity & extraction steps & \\
\hline Cell phone-based polarized light & Cell phone & Sensitivity & Not affordable & 75,76 \\
\hline \multirow[t]{2}{*}{ microscopy platform } & Polarized light microscopy system & Specificity & Not portable & \\
\hline & & User-friendly & & \\
\hline \multirow[t]{4}{*}{ Cell phone dongle platform } & Cell phone & Rapid & Not sensitive and & 15,77 \\
\hline & A dongle system with plastic & Portable & accurate enough & \\
\hline & cassettes & Affordable & & \\
\hline & Gold nanoparticles and silver ions & User-friendly & & \\
\hline \multirow[t]{5}{*}{ Paper-based POCT platforms } & Silver nanoparticles & Rapid & Not sensitive and & 78,79 \\
\hline & Lateral flow system & Portable & accurate enough & \\
\hline & & Affordable & & \\
\hline & & Equipment-free & & \\
\hline & & User-friendly & & \\
\hline
\end{tabular}

Abbreviations: NMR, nuclear magnetic resonance; POC, point-of-care; POCT, point-of-care test.

by using magnetic nanoparticles as proximity sensors. The DMR sensor is functioned by a self-amplifying proximity test with magnetic nanoparticles. ${ }^{80}$ The soluble nanoclusters resulting in a decrease in the bulk spin-spin relaxation time were formed through the conjugations between magnetic nanoparticles and the target molecules or proteins. The final results could be electronically recorded through the nuclear magnetic resonance (NMR) technique, which is faster than the surface structure-based nanodevices that need more time to prepare the samples and target the pathogenic agents. This feature also made them suitable to test blood, urine, or sputum samples with limited or no preparation procedures. A pilot trial has demonstrated that the miniaturized NMR system could overcome the low NMR signal level even without external magnetic fields, and was able to detect bacteria and identify protein biomarkers simultaneously. ${ }^{71}$ It is predictable that this miniaturized DMR platform, in combination with microfabrication strategies, could be used as a portable, low-cost, and high-throughput POC nanodiagnostics system for the large-scale detection of infectious diseases in the future.

The miniaturized DMR system could also be utilized for rapid profiling of infecting agents directly in clinical samples. ${ }^{72}$ Some ubiquitous and specific novel magneto-DNA probes were developed for sensitive and specific targeting bacterial 16S rRNAs using a nanoparticle hybridization assay through the miniaturized DMR platforms. The universal and specific detection of various clinically relevant infecting agents could have the single bacteria sensitivity. Moreover, the diagnosis has the ability to rapid profile infecting agents directly and simultaneously detects a panel of 13 pathogens within 2 hours in clinical specimens. This magneto-DNA approach-based miniaturized DMR platform has considerable advantages over standard culture and real-time PCR systems according to the assay times and costs.

\section{Magnetic barcode assay system}

The nanodevice-based diagnostic platforms have been developed for the sensitive and robust diagnosis of M. tuberculosis for tuberculosis infectious diseases ${ }^{73}$ however, the fast identification of tuberculosis patients in the developing countries still remains a big challenge currently. In response to this challenge, a magnetic barcode assay system has been proposed for the quick detection of nucleic acids from infecting pathogens in only 2.5 hours. As shown in Figure 3, all of the components were integrated into a small fluidic chip. The DNA extraction could be finished in 30 minutes from the offchip method. The target DNA sequence can be captured by polymer beads conjugated with capture DNA and magnetic nanoprobes through complementary sequences. Asymmetric PCR was used to amplify the signal of target DNA, followed by application of a portable NMR system to produce the desired signals. This diagnostic system could supply analytical NMR signals for nucleic acid detection of infecting pathogens. Except for the DNA extraction, all the procedures were operated in the integrated microfluidic systems. Upon the magnetic labeling and on-chip PCR amplification, the target samples were purified and concentrated in a microcoil using the membrane filter, and then the final results were recorded by a portable NMR platform. The sensitivity and 

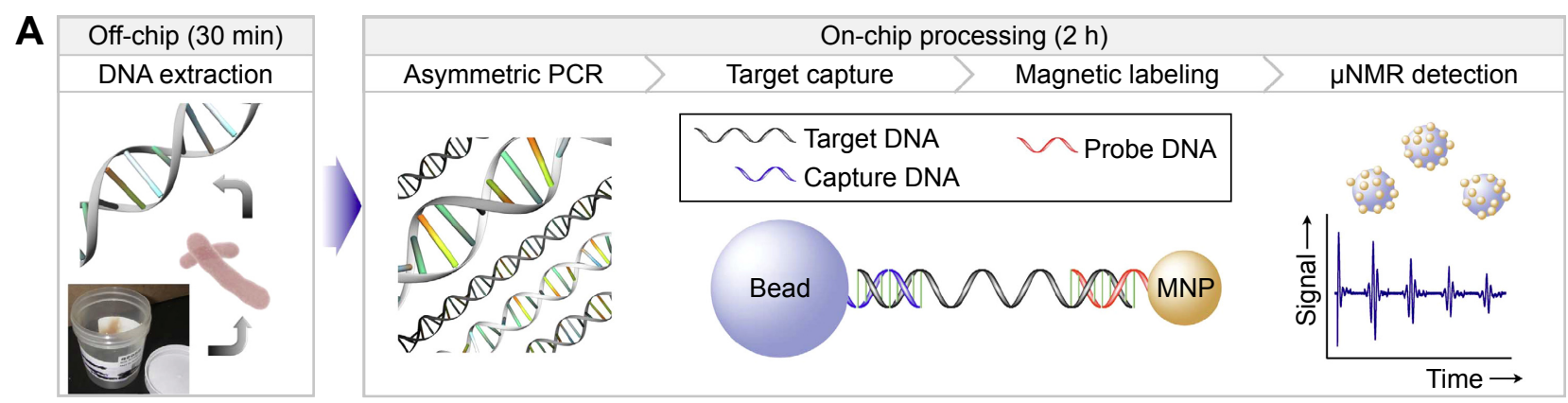

\section{B Torque-activated}

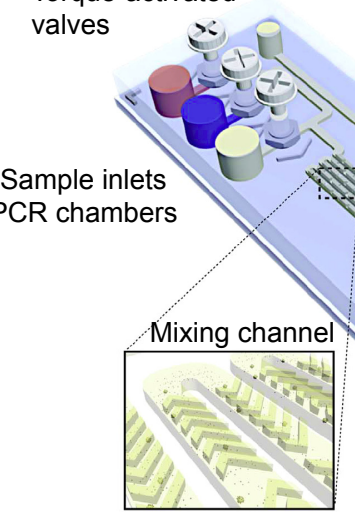

d.

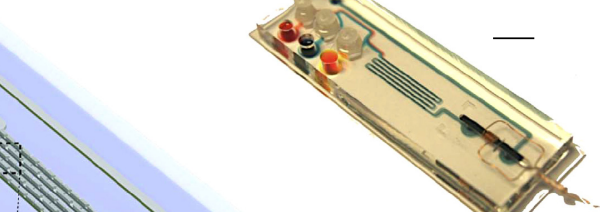

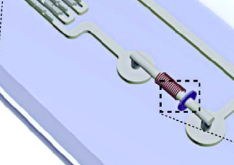

Sor
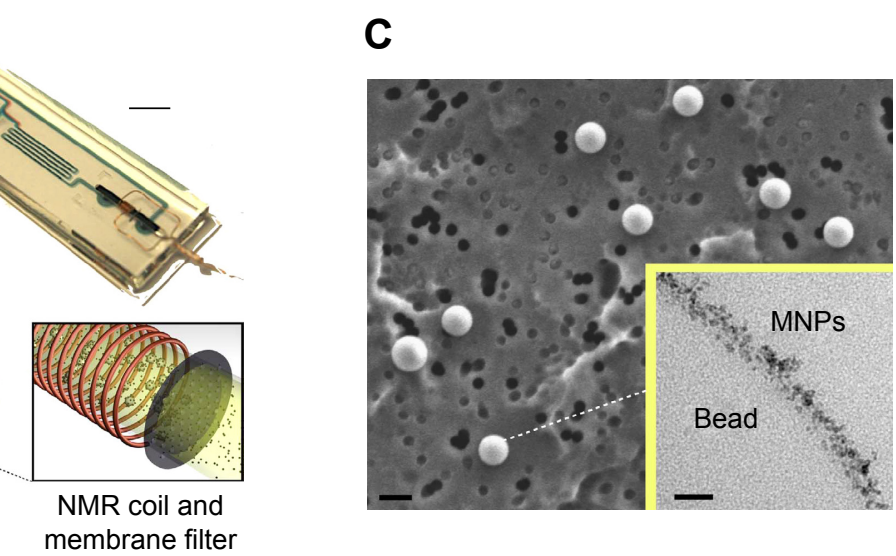

Figure 3 Point-of-care nanodiagnostics for tuberculosis through magnetic barcode assay.

Notes: (A) The procedure of the assay including off-chip DNA extraction, asymmetric PCR, target capture, magnetic labeling, and $\mu$ NMR detection. (B) The illustration of the fluidic cartridge that was used to streamline the assay (scale bar $=1 \mathrm{~cm})$. (C) The scanning (scale bar $=1 \mu \mathrm{m})$ and transmission $(\mathrm{scale}$ bar $=30 \mathrm{~nm}$, inset) electron microscopy demonstrated that the beads were captured by the membrane filters and labeled with MNPs. Reprinted by permission from Macmillan Publishers Ltd: Nature Communications. Liong M, Hoang A, Chung J, et al. Magnetic barcode assay for genetic detection of pathogens. 2013;4:1752. Copyright 2013. ${ }^{73}$

Abbreviations: MNPs, magnetic nanoparticles; NMR, nuclear magnetic resonance; PCR, polymerase chain reaction.

specificity of this diagnosis have already been confirmed through the detection of bacteria from tuberculosis patients and healthy people. ${ }^{73}$

The magnetic barcode system has also been successfully utilized in the multiplex detection of the most representative infectious bacteria such as Staphylococcus aureus, methicillin-resistant Staphylococcus aureus, and Klebsiella pneumoniae. ${ }^{74}$ In this novel POCT system, the fluorescent nanoparticle QDs and magnetic particles were used, and according to the changes in emission maxima of CdTe QDs modified by specific targeting bacteria specific genes such as wcaG, fnbA, and mecA, this POCT platform has the ability to detect the infectious bacteria concentrations as low as $10^{2} \mathrm{CFU} / \mathrm{mL}$. From our perspective, these portable magnetic barcode assay systems have potential in POC diagnosis for the sensitive, efficient, rapid, and low-cost detection of many other infectious diseases.

\section{Cell phone-based polarized light microscopy platform}

Immunology-based diagnosis of infectious diseases usually generates a color for positive samples. However, the signal is always too weak for the visible readouts for POCT because of the limited concentration of target pathogens or low volume of samples from infected patients. Recently, cell phones, integrated with a transmission polarized light microscope platform, have shown big promise for the POCT diagnosis for infectious diseases. ${ }^{15,67,81}$ A low-cost and optical cell phonebased transmission polarized light microscope platform has been developed to detect hemozoin for malaria, an infectious disease. ${ }^{75}$ This parasite is very difficult to be observed and recognized from the background items or other parasites by using the conventional microscope techniques, even for highly trained skilled technicians. Although the polarized light microscopy has more advantages for detection of this parasite for infectious diseases, the cost for the instruments, technicians training, and other resources are too much to be utilized. Thus, the newly developed cell phone-based polarized light microscopy platform could be more promising than the larger bench-top system. The three-dimensional printed accessories were used to integrate the iPhone 5 s cell phone camera and the microscope lens with $40 \times$ magnification, which could have the similar functions as the original large-scale laboratory microscope setup. The resolution and field of view 
characterization, malaria bright field and polarized imaging, and non-malaria polarized light comparative sample testing were operated to produce the results. A Leica polarized white light microscope was utilized as a positive reference for the comparison. Therefore, as compared to the larger bench-top system, it potentiates to have high fidelity and optical resolution, as well as enough specificity to detect malarial parasites with simple, low-cost, and user-friendly characteristics. ${ }^{75}$

Another successful pilot study to use the cellphone microscope for the POCT is the sensitive and specific quantification of blood-borne filarial parasites. ${ }^{76}$ Filarial parasite Loa loa has caused severe issues in central Africa. This system has a lot of potential to diagnose and control this infectious disease based on the automatic quantification of Loa loa microfilariae in whole blood. The blood samples could be collected in a small glass capillary from a finger prick and there is no need of the conventional sample preparation and staining procedures. A pilot study showed that the diagnosis reached a $100 \%$ sensitivity and $94 \%$ specificity from 33 potentially Loa loa-infected patients.

\section{Cell phone-based dongle platform}

Cell phones have been widely investigated for the application of POC diagnostics because of their user-friendly interface, fast computing function, wireless data processing, and declining prices. ${ }^{82}$ Most previous studies focused on the utilization of just one function from the cellphone, such as data processing or camera. It is difficult for those platforms to meet the ASSURED criteria in POC diagnosis for infectious diseases. ${ }^{82}$ Recently, a very novel nanodiagnostics platform, replicating the full laboratory quality immunoassay into a cell phone accessory, has been developed (Figure 4). This is one of the most successful promising POC nanodiagnostic systems that could be used in clinical environments in the future. ${ }^{15}$ In this system, a small and light dongle was designed to have the similar function with an ELISA microplate assay using disposable plastic cassettes preloaded with reagents. The gold nanoparticles and silver ions were used for the amplification steps instead of enzymes and substrate in ELISA systems. ${ }^{83}$ All the mechanical, electronic, and optical functions were operated using the power from a cell phone in this system. These features make them very unique from the previous nanodiagnostic platforms that need external energy or resources for the sensing purposes. The whole blood from 96 patients with the potential blood-borne infectious disease through finger prick methods was used to test the detecting capabilities of the cell phone-based dongle platform. The triplexed immunoassay using HIV antibody, treponemal specific syphilis antibody, and nontreponemal antibody for active syphilis infection were operated in a single test from this platform. The test results could be obtained in 15 minutes from the triplex assays in a blinded experiment, by which a detecting specificity from $79 \%$ to $100 \%$, and sensitivity from $92 \%$ to $100 \%$ were demonstrated. Patients are more likely to prefer (97\%) this dongle system with quick results from a single finger prick than the conventional ELISA tests.

Recently, a similar cellphone dongle system has also been developed for the detection of hemoglobin concentration and measurement of HIV antibodies successfully. ${ }^{77}$ In this system, an immunoassay device was expanded to quantitatively detect hemoglobin concentration and HIV antibodies through colorimetric measurement of the optical density of silver precipitation on gold nanoparticles. It has been demonstrated that the HIV immunoassay in the presence of CHAPs detergent could have 95\% specificity and 95\% sensitivity. These cell phone-based dongle platforms not only demonstrated their abilities for the HIV and syphilis diagnosis in a real POCT manner, but also supplied a new direction for the development of novel nanodiagnostics platforms with integrated nanotechnology, microtechnology, and consumer electronics for POC diagnosis of infectious diseases in the future.

\section{Paper-based POCT platform}

The unique properties of paper, such as being low cost, portable, and disposable, make it very suitable for the POC diagnosis. Different paper-based POCT platforms with visible readouts have been intensively studied for the diagnosis of infectious disease. ${ }^{67}$ In combination with multicolored silver nanoplates, a novel paper-based POC diagnostic platform for multiplexed detection of infecting pathogens has recently been proposed. ${ }^{78}$ Based on multiplexed lateral flow system, the paper-based POCT platforms showed a rapid testing speed and an ability to detect multiple infecting pathogens simultaneously by using only one individual strip. ${ }^{84}$ These characteristics make them very suitable for the POC diagnosis of infectious disease because of their simple, low-cost, and robust properties ${ }^{85}$ As shown in Figure 5, this lateral flow system-based paper POCT platform was composed of an absorbent pad (wick), nitrocellulose membrane, conjugate pad (CP), and sample pad. The triangular plate-shaped silver nanoparticles conjugated with different antibodies, which could result in easily distinguishable colors due to the size-tunable absorption spectra of silver nanoparticles, were preloaded in the $\mathrm{CP}$. The antibodies recognizing yellow fever virus NS1 protein, Ebola virus, Zaire strain glycoprotein GP, and dengue virus NS1 protein were used to conjugate with the triangular plate-shaped silver nanoparticles for the 


\section{A}

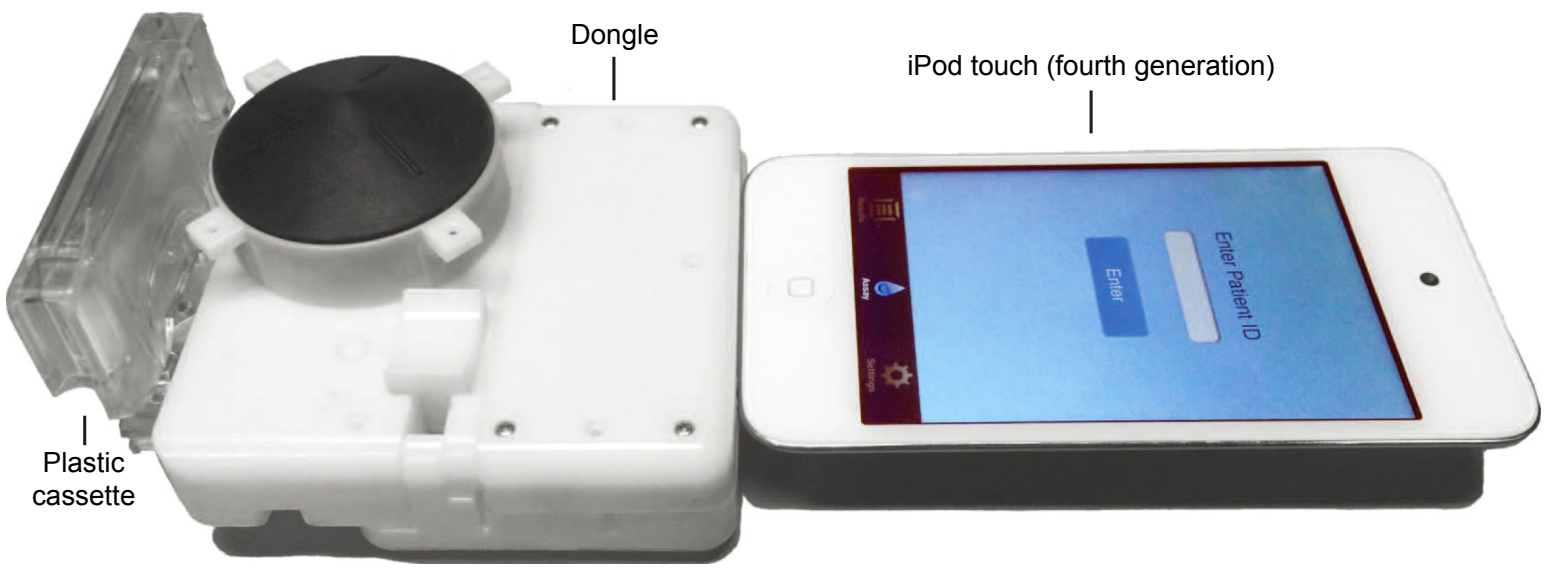

B

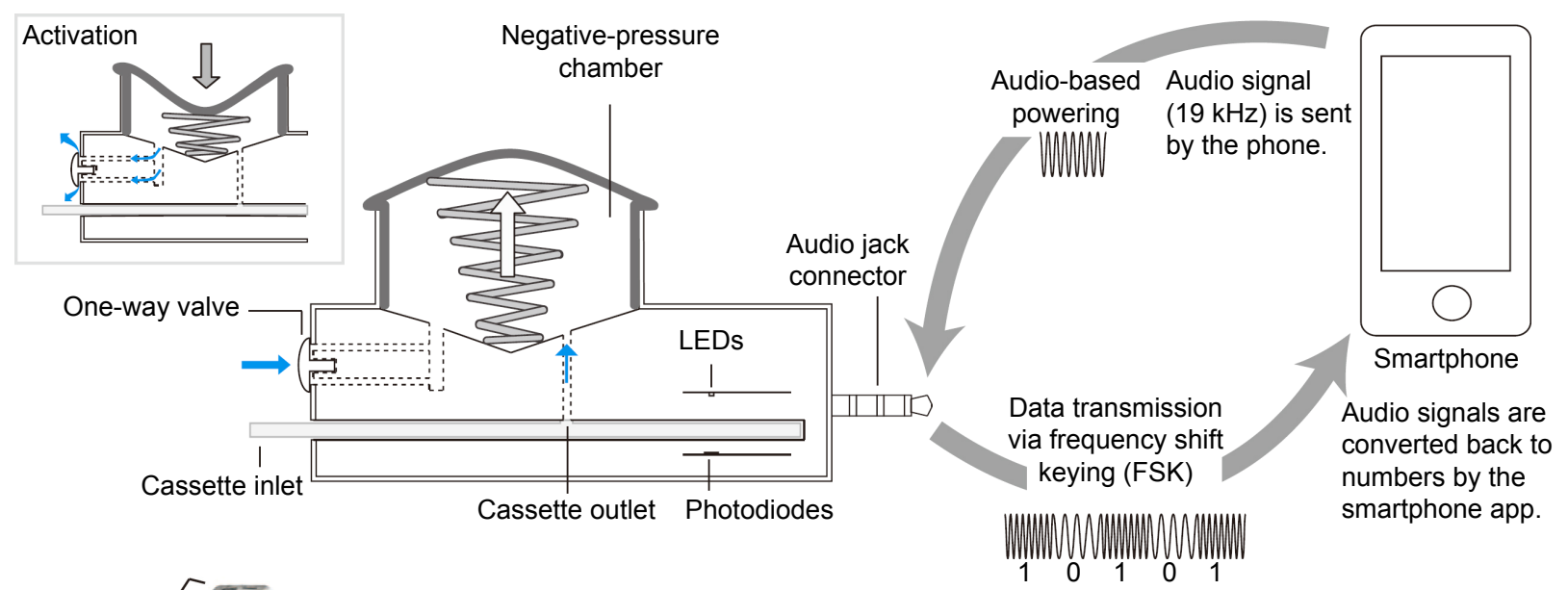

C
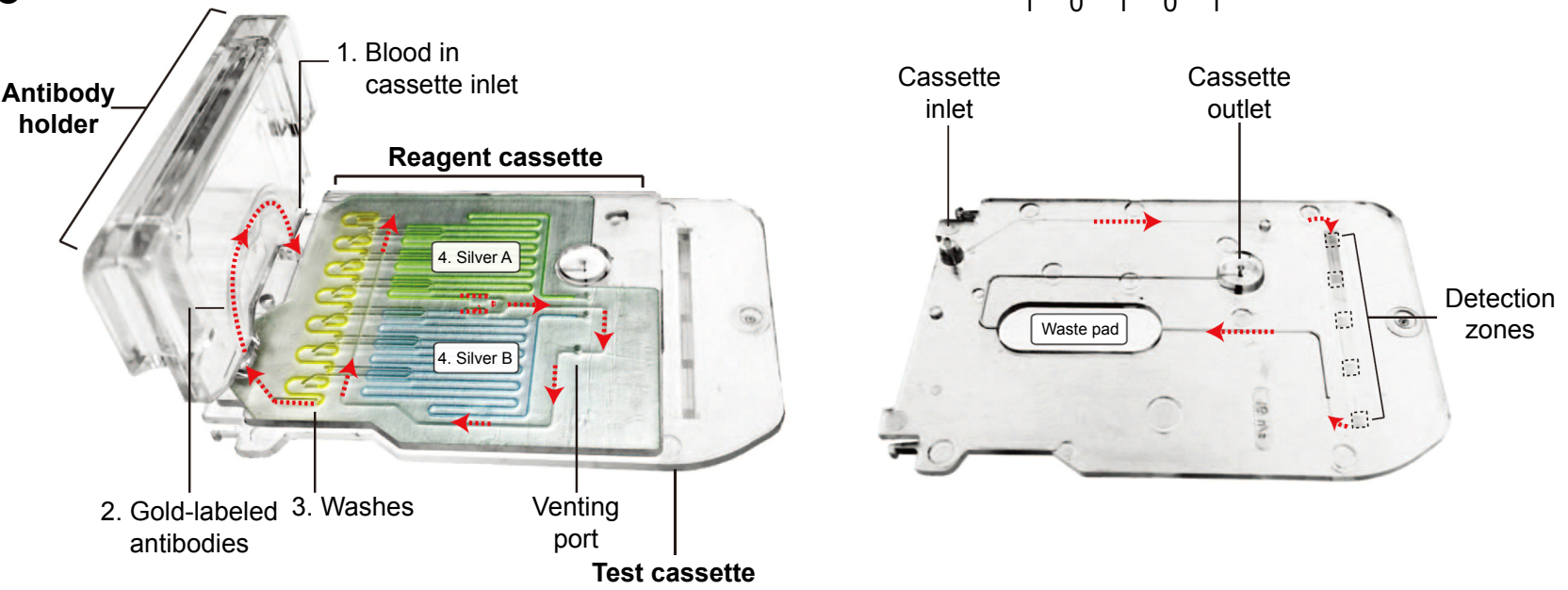

D

\begin{tabular}{|c|c|c|c|c|}
\hline & \multicolumn{2}{|l|}{ ELISA } & \multicolumn{2}{|l|}{ Smartphone dongle } \\
\hline & Method & Cost (USD) & Method & Cost (USD) \\
\hline Electronics & Plate reader & $\$ 8,850$ & Custom PCB (outsource manufacturing in China) & $\$ 31$ \\
\hline Communication & Data acquistion cable & - & FSK via audio jack & - \\
\hline Mechanical & Plate washer & $\$ 9,600$ & Power-free vacuum pump (injection moldable case) & $\$ 3$ \\
\hline Total & & $\begin{array}{l}\$ 18,450 \\
+ \text { computer }\end{array}$ & & $\begin{array}{l}\$ 34 \\
+ \text { smartphone }\end{array}$ \\
\hline
\end{tabular}

Figure 4 Overview of the cell phone-based point-of-care diagnosis for human immunodeficiency virus and syphilis.

Notes: (A) The iPod touch connected to the dongle with a microfluidic cassette. (B) Schematic illustration of dongle with a power-free vacuum generator. (C) Left: The reagent cassette that contains prestored reagents at the top layer and the test cassette at the bottom layer. Right: The flow sequences through test cassette. (D) Comparison of conventional ELISA versus the dongle for the diagnostic test. From Laksanasopin T, Guo T, Nayak S, et al. A smartphone dongle for diagnosis of infectious disease at the point-ofcare. Science Translational Medicine. 2015;7(273):273rel. Reprinted with permission from AAAS. Copyright 2015 The American Association for the Advancement of Science. ${ }^{15}$ Abbreviations: ELISA, enzyme-linked immunosorbent assay; LEDs, light-emitting diodes. 
A
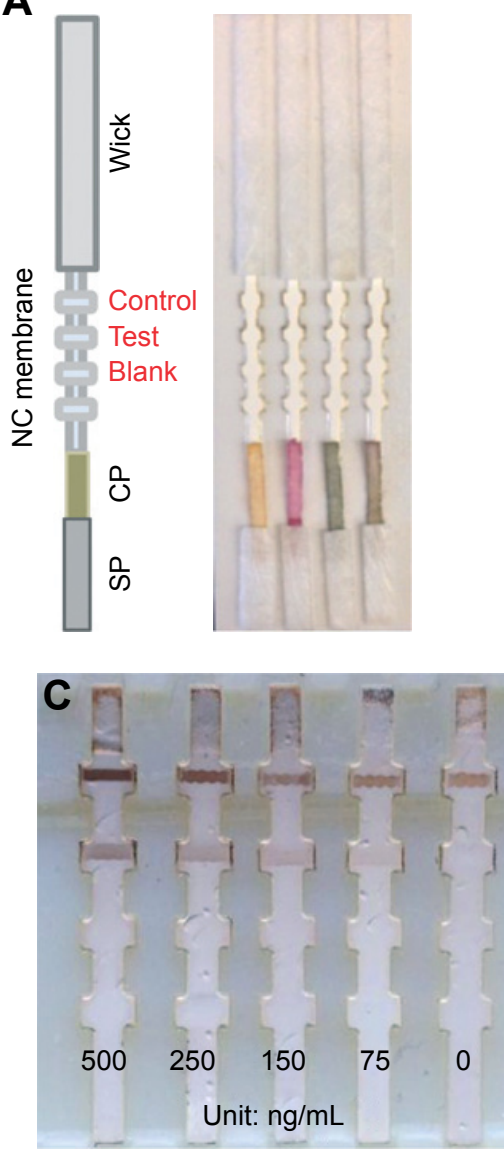

B
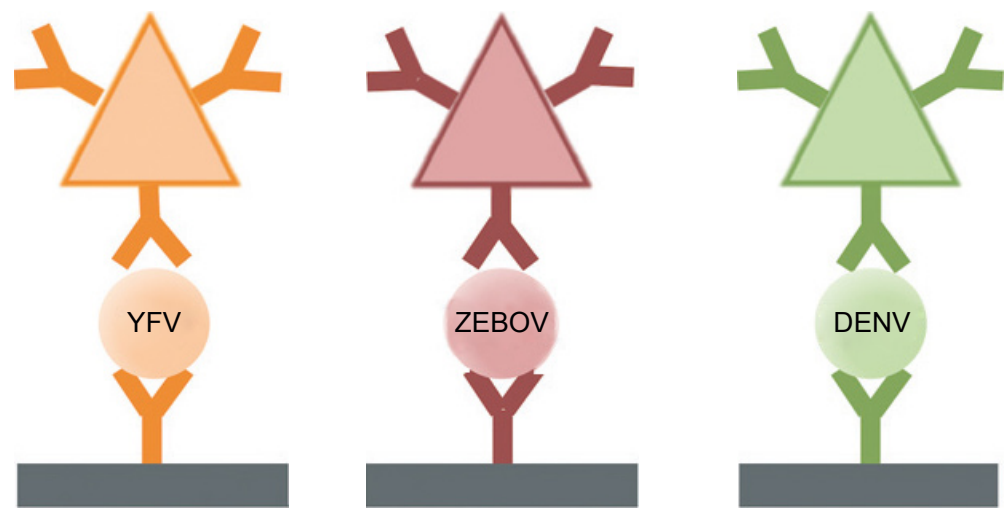

Nitrocellulose membrane
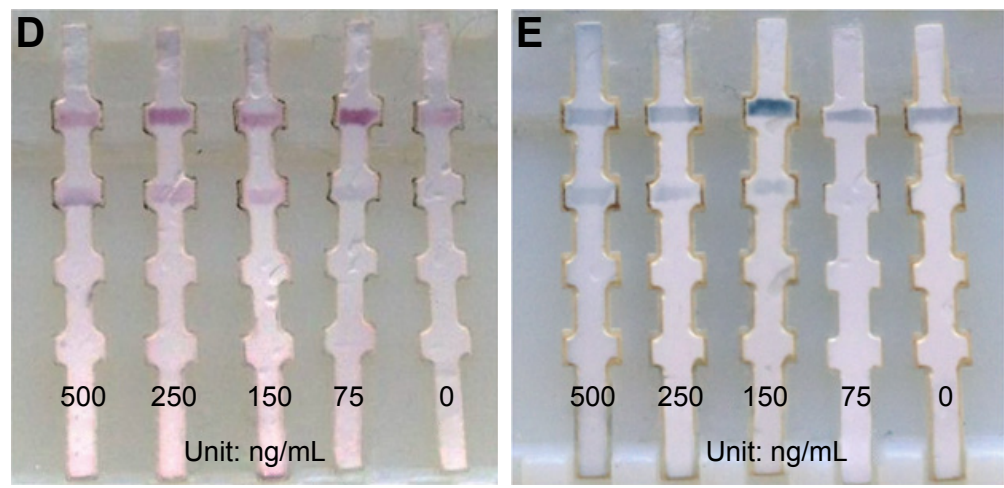

Figure 5 Paper-based point-of-care nanodiagnostic platform for the detection of YFV, ZEBOV, and DENV using AgNPs for infectious diseases.

Notes: (A) Lateral flow strips with CP loaded individually with orange, red, and green AgNPs conjugated to mAbs (from left to right). The size of strip is $20 \times 3 \mathrm{~mm}$. (B) Illustration of the sandwich assay. Limit of detection of (C) YFV NSI, (D) ZEBOV GP, and (E) DENV NSI using the different AgNP-Abs. Reproduced from Yen C, Puig H, Tam J, et al. Multicolored silver nanoparticles for multiplexed disease diagnostics: distinguishing dengue, yellow fever, and Ebola viruses. Lab Chip. 20I5; I5:I638-164I. DOI http://dx.doi.org//0.1039/C5LC00055F, with permission of The Royal Society of Chemistry. @ Royal Society of Chemistry. Available from: http://dx.doi.org//0.1039/ c5lc00055f. ${ }^{78}$

Abbreviations: AgNPs, silver nanoparticles; CP, conjugate pads; DENV, dengue virus; GP, glycoprotein; mAbs, monoclonal antibodies; NC, nitrocellulose; NSI, nonstructural protein I; SP, sample pad; YFV, yellow fever virus; ZEBOV, Ebola virus, Zaire stain.

sandwich assay. This diagnostic system could distinguish different biomarkers of infectious diseases by different color readout on the test lines, with detecting sensitivity of as low as $150 \mathrm{ng} / \mathrm{mL}$. More importantly, this nanodiagnostic platform can perform the multiplexed analysis without external excitation sources, which greatly featured it for the POC diagnosis of infectious diseases. ${ }^{78}$

Although this simple and promising paper-based POC nanodiagnostic platform has much potential to meet the ASSURED criteria for diagnosis applications in both developed and developing nations, there still remain several limitations, such as the detecting sensitivity and accuracy. For instance, a commercially available NanoSign ${ }^{\circledR}$ HBs POCT strip has been evaluated for its ability to detect HBsAg for hepatitis B infectious diseases. ${ }^{79}$ This POC nanodiagnostic system was utilized to screen serum samples from 297 patients with potential HBV infections. Only a 73.7\% detecting sensitivity and $97.8 \%$ specificity for HBsAg were confirmed. Moreover, false-negative results were frequently observed in a clinical setting, indicating that the sensitivity and specificity of this paper-based POC nanodiagnostic platform still needs to be improved.

\section{Conclusion and perspectives}

Nanodiagnostic technologies have been successfully applied in the diagnosis of infectious diseases. In this review, we provided an overview of recent trends in nanodiagnostics for infectious diseases from the perspectives of nanoparticlebased, nanodevice-based, and POCT platforms. With an emphasis on the nanotechnology-based POCT system, the most novel and promising POC nanodiagnostic platforms and systems, such as miniaturized DMR platform, magnetic barcode assay system, cell phone-based polarized light microscopy platform, cell phone-based dongle platform, and 
paper-based POCT platform, were fully discussed. Although they have many significant advantages over conventional diagnostic strategies such as low cost, portability, and disposability, they all are still in the early phase of development. Currently, the most promising POC nanodiagnostic devices may perform well in certain aspects, but they may fail to satisfy all the requirements of the ASSURED criteria. Therefore, multidisciplinary efforts are still needed from biological, engineered, and clinical perspectives for the development of highly integrated and novel POC nanodiagnostics that can promote the control and cure of infectious diseases worldwide.

\section{Acknowledgments}

This work was supported by the National Natural Science Foundation of China (YW, grant number 31470218; LY, grant number 81572022 ). The authors also thank the anonymous reviewers for their insightful suggestions on improving this original review article.

\section{Disclosure}

The authors report no conflicts of interest in this work.

\section{References}

1. Ray B, Ghedin E, Chunara R. Network inference from multimodal data: a review of approaches from infectious disease transmission.J Biomedi Infor. 2016;64:44-54.

2. Fauci AS, Morens DM. The perpetual challenge of infectious diseases. N Engl J Med. 2012;366(5):454-461.

3. Munoz-Price LS, Weinstein RA. Acinetobacter infection. $N$ Engl J Med. 2008;358(12):1271-1281.

4. Cohen MS, Shaw GM, McMichael AJ, Haynes BF. Acute HIV-1 infection. N Engl J Med. 2011;364(20):1943-1954.

5. Hauck TS, Giri S, Gao Y, Chan WCW. Nanotechnology diagnostics for infectious diseases prevalent in developing countries. Adv Drug Del Rev. 2010;62(4-5):438-448.

6. Ashley EA, Dhorda M, Fairhurst RM, et al. Spread of artemisinin resistance in Plasmodium falciparum Malaria. N Engl J Med. 2014; 371(5):411-423.

7. Galluzzi L, Buque A, Kepp O, Zitvogel L, Kroemer G. Immunogenic cell death in cancer and infectious disease. Nat Rev Immunol. 2017;17(2): 97-111.

8. World Health Organization. World malaria report 2016; 2016. Available from: http://apps.who.int/iris/bitstream/10665/252038/1/97892415117 11-eng.pdf. Accessed May 17, 2017.

9. Shinde SB, Fernandes CB, Patravale VB. Recent trends in in-vitro nanodiagnostics for detection of pathogens. J Control Rel. 2012;159(2): 164-180.

10. Kotloff KL, Nataro JP, Blackwelder WC, et al. Burden and aetiology of diarrhoeal disease in infants and young children in developing countries (the Global Enteric Multicenter Study, GEMS): a prospective, casecontrol study. Lancet. 2013;382(9888):209-222.

11. Wilson MR, Naccache SN, Samayoa E, et al. Actionable diagnosis of neuroleptospirosis by next-generation sequencing. $N$ Engl J Med. 2014;370(25):2408-2417.

12. Golding CG, Lamboo LL, Beniac DR, Booth TF. The scanning electron microscope in microbiology and diagnosis of infectious disease. Sci Rep. 2016;6:26516.
13. Li Z, Li D, Zhang D, Yamaguchi Y. Determination and quantification of Escherichia coli by capillary electrophoresis. Analyst. 2014; 139(23):6113-6117.

14. Bates M, Zumla A. Rapid infectious diseases diagnostics using smartphones. Ann Transl Med. 2015;3(15):215.

15. Laksanasopin T, Guo TW, Nayak S, et al. A smartphone dongle for diagnosis of infectious diseases at the point of care. Sci Transl Med.2015;7(273): 273 re1.

16. Sun L, Zheng C, Webster TJ. Self-assembled peptide nanomaterials for biomedical applications: promises and pitfalls. Int J Nanomed. 2017; 12:73-86.

17. Sun L, Yi S, Wang Y, Pan K, Zhong Q, Zhang M. A bio-inspired approach for in situ synthesis of tunable adhesive. Bioinspir Biomim. 2014;9(1):016005.

18. Sun L, Wanasekara N, Chalivendra V, Calvert P. Nano-mechanical studies on polyglactin sutures subjected to in vitro hydrolytic and enzymatic degradation. J Nanosci Nanotechnol. 2015;15(1):93-99.

19. Chai F, Sun L, Ding Y, et al. A solid self-nanoemulsifying system of the BCS class IIb drug dabigatran etexilate to improve oral bioavailability. Nanomedicine. 2016;11(14):1801-1816.

20. Sun L, Fan Z, Wang Y, Huang Y, Schmidt M, Zhang M. Tunable synthesis of self-assembled cyclic peptide nanotubes and nanoparticles. Soft Matter. 2015;11(19):3822-3832.

21. Wang Y, Yi S, Sun L, Huang Y, Zhang M. Charge-selective fractions of naturally occurring nanoparticles as bioactive nanocarriers for cancer therapy. Acta Biomater. 2014;10(10):4269-4284.

22. Sun L, Huang Y, Bian Z, et al. Sundew-inspired adhesive hydrogels combined with adipose-derived stem cells for wound healing. ACS Appl Mater Interfaces. 2016;8(3):2423-2434.

23. GBD 2013 Mortality and Causes of Death Collaborators. Global, regional, and national age-sex specific all-cause and cause-specific mortality for 240 causes of death, 1990-2013: a systematic analysis for the Global Burden of Disease Study 2013. Lancet. 2015;385(9963):117-171.

24. Deeks SG, Overbaugh J, Phillips A, Buchbinder S. HIV infection. Nature Rev Dis Primers. 2015;1:15035.

25. UNAIDS; Joint United Nations Programme on HIV/AIDS. Global AIDS update 2016; 2016. Available from: http://www.who.int/hiv/pub/arv/ global-AIDS-update-2016_en.pdf?ua=1. Accessed May 17, 2017.

26. Maartens G, Celum C, Lewin SR. HIV infection: epidemiology, pathogenesis, treatment, and prevention. Lancet. 2014;384(9939):258-271.

27. World Health Organization. Global health sector strategy on viral hepatitis 2016-2021. Towards ending viral hepatitis; 2016. Available from: http://apps.who.int/iris/bitstream/10665/246177/1/WHO-HIV2016.06-eng.pdf. Accessed May 17, 2017.

28. Duan L, Wang Y, Li SS-c, Wan Z, Zhai J. Rapid and simultaneous detection of human hepatitis $B$ virus and hepatitis $C$ virus antibodies based on a protein chip assay using nano-gold immunological amplification and silver staining method. BMC Infect Dis. 2005;5(1):53.

29. Lee SY, Lee CN, Mark H, Meldrum DR, Lin CW. Efficient, specific, compact hepatitis B diagnostic device: optical detection of the hepatitis B virus by isothermal amplification. Sens Actuators B. 2007;127(2):598-605.

30. Godreuil S, Tazi L, Bañuls A-L. Pulmonary tuberculosis and mycobacterium tuberculosis: modern molecular epidemiology and perspectives. In: Encyclopedia of Infectious Diseases. Hoboken, NJ: John Wiley \& Sons, Inc.; 2006:1-29.

31. World Health Organization. Global tuberculosis report 2016; 2016. Available from: http://apps.who.int/iris/bitstream/10665/250441/1/97 89241565394-eng.pdf?ua=1. Accessed May 17, 2017.

32. Pfyffer GE, Wittwer F. Incubation time of mycobacterial cultures: how long is long enough to issue a final negative report to the clinician? J Clin Microbiol. 2012;50(12):4188-4189.

33. Wang S, Inci F, De Libero G, Singhal A, Demirci U. Point-of-care assays for tuberculosis: role of nanotechnology/microfluidics. Biotechnol Adv 2013;31(4):438-449.

34. Bell D, Wongsrichanalai C, Barnwell JW. Ensuring quality and access for malaria diagnosis: how can it be achieved? Nat Rev Micro. 2006; 4(9):682-695. 
35. van Eijk AM, Hill J, Noor AM, Snow RW, ter Kuile FO. Prevalence of malaria infection in pregnant women compared with children for tracking malaria transmission in sub-Saharan Africa: a systematic review and meta-analysis. Lancet Glob Health. 2015;3(10):e617-e628.

36. Echeverry DF, Deason NA, Davidson J, et al. Human malaria diagnosis using a single-step direct-PCR based on the Plasmodium cytochrome oxidase III gene. Malar J. 2016;15(1):128.

37. Chua KH, Lee PC, Chai HC. Development of insulated isothermal PCR for rapid on-site malaria detection. Malar J. 2016;15(1):134.

38. Walk J, Schats R, Langenberg MCC, et al. Diagnosis and treatment based on quantitative PCR after controlled human malaria infection. Malar J. 2016;15(1):398.

39. Branson BM. State of the art for diagnosis of HIV infection. Clin Infect Dis. 2007;45(Suppl_4):S221-S225.

40. Baptista PV. Nanodiagnostics: leaving the research lab to enter the clinics? Diagnosis. 2014;1(4):305-309.

41. Tallury P, Malhotra A, Byrne LM, Santra S. Nanobioimaging and sensing of infectious diseases. Adv Drug Del Rev. 2010;62(4-5):424-437.

42. Fan T, Yu X, Shen B, Sun L. Peptide self-assembled nanostructures for drug delivery applications. J Nanomater. 2017;2017:16.

43. Kaittanis C, Santra S, Perez JM. Emerging nanotechnology-based strategies for the identification of microbial pathogenesis. Adv Drug Deliv Rev. 2010;62(4-5):408-423.

44. Zhang P, Lu H, Chen J, Han H, Ma W. Simple and sensitive detection of HBsAg by using a quantum dots nanobeads based dot-blot immunoassay. Theranostics. 2014;4(3):307-315.

45. Mirkin CA, Letsinger RL, Mucic RC, Storhoff JJ. A DNA-based method for rationally assembling nanoparticles into macroscopic materials. Nature. 1996;382(6592):607-609

46. Darbha GK, Rai US, Singh AK, Ray PC. Gold-nanorod-based sensing of sequence specific HIV-1 virus DNA by using hyper-rayleigh scattering spectroscopy. Chemistry. 2008;14(13):3896-3903.

47. Griffin J, Singh AK, Senapati D, et al. Sequence-specific HCV RNA quantification using the size-dependent nonlinear optical properties of gold nanoparticles. Small. 2009;5(7):839-845.

48. Wu W, Jiang CZ, Roy VAL. Designed synthesis and surface engineering strategies of magnetic iron oxide nanoparticles for biomedical applications. Nanoscale. 2016;8(47):19421-19474.

49. Kolosnjaj-Tabi J, Lartigue L, Javed Y, et al. Biotransformations of magnetic nanoparticles in the body. Nano Today. 2016;11(3):280-284.

50. Duguet E, Vasseur S, Mornet S, Devoisselle J-M. Magnetic nanoparticles and their applications in medicine. Nanomedicine. 2006;1(2):157-168.

51. Gu H, Xu K, Xu C, Xu B. Biofunctional magnetic nanoparticles for protein separation and pathogen detection. Chem Commun. 2006;(9): 941-949.

52. Moraes Silva S, Tavallaie R, Sandiford L, Tilley RD, Gooding JJ. Gold coated magnetic nanoparticles: from preparation to surface modification for analytical and biomedical applications. Chem Commun. 2016; 52(48):7528-7540.

53. Yuen C, Liu Q. Magnetic field enriched surface enhanced resonance Raman spectroscopy for early malaria diagnosis. BIOMEDO. 2012;17(1):0170051-0170057.

54. Dixon C, Ng AHC, Fobel R, Miltenburg MB, Wheeler AR. An inkjet printed, roll-coated digital microfluidic device for inexpensive, miniaturized diagnostic assays. Lab Chip. 2016;16(23):4560-4568.

55. Cabibbe AM, Miotto P, Moure R, et al. Lab-on-chip-based platform for fast molecular diagnosis of multidrug-resistant tuberculosis. J Clin Microbiol. 2015;53(12):3876-3880.

56. Tay A, Pavesi A, Yazdi SR, Lim CT, Warkiani ME. Advances in microfluidics in combating infectious diseases. Biotechnol Adv. 2016;34(4): 404-421.

57. Dittrich PS, Manz A. Lab-on-a-chip: microfluidics in drug discovery. Nat Rev Drug Discov. 2006;5(3):210-218.

58. Murdock RC, Gallegos KM, Hagen JA, Kelley-Loughnane N, Weiss AA, Papautsky I. Development of a point-of-care diagnostic for influenza detection with antiviral treatment effectiveness indication. Lab Chip. 2017;17(2):332-340.
59. Sackmann EK, Fulton AL, Beebe DJ. The present and future role of microfluidics in biomedical research. Nature. 2014;507(7491): 181-189.

60. Li Z, Zhao Y, Zhang D, Zhuang S, Yamaguchi Y. The development of a portable buoyancy-driven PCR system and its evaluation by capillary electrophoresis. Sens Actuators B. 2016;230:779-784.

61. Su W, Gao X, Jiang L, Qin J. Microfluidic platform towards point-ofcare diagnostics in infectious diseases. J Chromatogr A. 2015;1377: $13-26$.

62. Klostranec JM, Xiang Q, Farcas GA, et al. Convergence of quantum dot barcodes with microfluidics and signal processing for multiplexed high-throughput infectious disease diagnostics. Nano Lett. 2007;7(9): 2812-2818.

63. Cheng K, El-Boubbou K, Landry CC. Binding of HIV-1 gp120 glycoprotein to silica nanoparticles modified with $\mathrm{CD} 4$ glycoprotein and CD4 peptide fragments. ACS Appl Mater Interfaces. 2012;4(1): 235-243.

64. Warkiani ME, Tay AKP, Khoo BL, Xiaofeng X, Han J, Lim CT. Malaria detection using inertial microfluidics. Lab Chip. 2015;15(4): 1101-1109.

65. Kim JH, Yeo WH, Shu Z, et al. Immunosensor towards low-cost, rapid diagnosis of tuberculosis. Lab Chip. 2012;12(8):1437-1440.

66. Yeo WH, Chung JH, Liu Y, Lee KH. Size-specific concentration of DNA to a nanostructured tip using dielectrophoresis and capillary action. J Phys Chem B. 2009;113(31):10849-10858.

67. Tram DTN, Wang H, Sugiarto $\mathrm{S}$, et al. Advances in nanomaterials and their applications in point of care (POC) devices for the diagnosis of infectious diseases. Biotechnol Adv. 2016;34(8):1275-1288.

68. Wu G, Zaman MH. Low-cost tools for diagnosing and monitoring HIV infection in low-resource settings. Bull World Health Organ. 2012;90(12):914-920.

69. Mabey D, Peeling RW, Ustianowski A, Perkins MD. Tropical infectious diseases: diagnostics for the developing world. Nat Rev Micro. 2004;2(3):231-240.

70. Scardino PT, Hay AM. Point of care testing: a welcome advance? Nat Clin Pract Urol. 2007;4(8):401

71. Lee H, Sun E, Ham D, Weissleder R. Chip-NMR biosensor for detection and molecular analysis of cells. Nat Med. 2008;14(8):869-874.

72. Chung HJ, Castro CM, Im H, Lee H, Weissleder R. A magneto-DNA nanoparticle system for rapid detection and phenotyping of bacteria. Nat Nano. 2013;8(5):369-375.

73. Liong M, Hoang AN, Chung J, et al. Magnetic barcode assay for genetic detection of pathogens. Nat Commun. 2013;4:1752

74. Cihalova K, Hegerova D, Jimenez AM, et al. Antibody-free detection of infectious bacteria using quantum dots-based barcode assay. J Pharm Biomed Anal. 2017;134:325-332.

75. Pirnstill CW, Coté GL. Malaria Diagnosis Using a Mobile Phone Polarized Microscope. Scientific Reports. 2015;5:13368.

76. D'Ambrosio MV, Bakalar M, Bennuru S, et al. Point-of-care quantification of blood-borne filarial parasites with a mobile phone microscope. Sci Transl Med. 2015;7(286):286re4.

77. Guo T, Patnaik R, Kuhlmann K, Rai AJ, Sia SK. Smartphone dongle for simultaneous measurement of hemoglobin concentration and detection of HIV antibodies. Lab Chip. 2015;15(17):3514-3520.

78. Yen CW, de Puig H, Tam JO, et al. Multicolored silver nanoparticles for multiplexed disease diagnostics: distinguishing dengue, yellow fever, and Ebola viruses. Lab Chip. 2015;15(7):1638-1641.

79. Gish RG, Gutierrez JA, Navarro-Cazarez N, et al. A simple and inexpensive point-of-care test for hepatitis B surface antigen detection: serological and molecular evaluation. $J$ Viral Hepat. 2014;21(12): 905-908.

80. Perez JM, Josephson L, O’Loughlin T, Hogemann D, Weissleder R. Magnetic relaxation switches capable of sensing molecular interactions. Nat Biotech. 2002;20(8):816-820.

81. Smith ZJ, Chu K, Espenson AR, et al. Cell-phone-based platform for biomedical device development and education applications. PLos One. 2011;6(3):e17150. 
82. Zurovac D, Sudoi RK, Akhwale WS, et al. The effect of mobile phone text-message reminders on Kenyan health workers' adherence to malaria treatment guidelines: a cluster randomised trial. Lancet. 2011; 378(9793):795-803.

83. Chin CD, Laksanasopin T, Cheung YK, et al. Microfluidics-based diagnostics of infectious diseases in the developing world. Nat Med. 2011;17(8):1015-1019.
84. Fenton EM, Mascarenas MR, López GP, Sibbett SS. Multiplex lateralflow test strips fabricated by two-dimensional shaping. ACS Appl Mater Interfaces. 2009;1(1):124-129.

85. GeißlerD, Charbonnière LJ, Ziessel RF, Butlin NG, Löhmannsröben H-G, Hildebrandt N. Quantum dot biosensors for ultrasensitive multiplexed diagnostics. Angew Chem Int Ed Engl. 2010;49(8):1396-1401.
International Journal of Nanomedicine

\section{Publish your work in this journal}

The International Journal of Nanomedicine is an international, peerreviewed journal focusing on the application of nanotechnology in diagnostics, therapeutics, and drug delivery systems throughout the biomedical field. This journal is indexed on PubMed Central, MedLine, CAS, SciSearch $®$, Current Contents $® /$ Clinical Medicine,

\section{Dovepress}

Journal Citation Reports/Science Edition, EMBase, Scopus and the Elsevier Bibliographic databases. The manuscript management system is completely online and includes a very quick and fair peer-review system, which is all easy to use. Visit http://www.dovepress.com/ testimonials.php to read real quotes from published authors.

Submit your manuscript here: http://www.dovepress.com/international-journal-of-nanomedicine-journal 